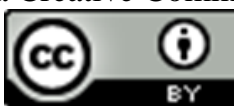

\title{
SAÚDE MENTAL EM TERRITÓRIOS SEGREGADOS: CLIINICA DA VIOLÊNCIA RACISTA-SEXISTA E FORMAÇÃO EM PSICOLOGIA
}

\author{
Regina Marques de Souza Oliveira ${ }^{1}$ \\ Railton da Conceição dos Santos ${ }^{2}$ \\ Jaqueline Alves Fonseca ${ }^{3}$ \\ Núbia dos Reis Pinto ${ }^{4}$ \\ Reinaldo José de Oliveira ${ }^{5}$
}

Resumo: A segregação ocorre onde o poder público é ausente e faltam equipamentos de saúde, educação e lazer de qualidade. A periferia é um território em geral segregado da cidade e é habitado pelas populações negras e brancos pobres. Neste trabalho desenvolvemos em uma instituição escolar na cidade de Santo Antônio de Jesus ações de promoção em saúde mental direcionadas a população que habita a periferia. A metodologia constitui-se por oficinas de saúde, rodas de conversas temáticas e escuta das vivências de jovens e seus familiares e professores no espaço escolar. As atividades organizaram-se através de leituras sociológicas, étnico-raciais, psicanalíticas e da psicologia social. As atividades lúdicas e oficinas promoveram o diálogo sobre questões como racismo, homofobia, segregação, sexismo, dentre outros. Os resultados apontam que inserir-se nos contextos periféricos da juventude negra através da psicologia é promover o acolhimento a saúde mental e fortalecimento da crítica social para a transformação política da sociedade a partir das ações promovidas pelos próprios sujeitos implicados no contexto.

Palavras-chave: racismo, violência, saúde mental, cidadania, formação em psicologia.

\footnotetext{
${ }^{1}$ Professora Doutora na Universidade Federal do Recôncavo da Bahia - Orientadora do PIBEX. E-mail: marquesregina@uol.com.br, Orcid: https://orcid.org/0000-0003-3720-0922

${ }^{2}$ Graduando no Bacharelado Interdisciplinar em Saúde na UFRB - Extensionista Bolsista do PIBEX. Email: rayltonsantos017@gmail.com ; Orcid: https://orcid.org/0000-0002-1279-9353

${ }^{3}$ Graduanda no Bacharelado Interdisciplinar em Saúde na UFRB - Extensionista voluntária do PIBEX. Email: jaquefonseka81@ gmail.com , Orcid: https//orcid.org//0000-0002-9543-3671
}

4 Mestre em Ciências Sociais, UFBA. NEPPINS, UFRB. E-mail: nubiarpinto@gmail.com ; Orcid: https://orcid.org/0000-0001-8508-8264

5 Professor Doutor no Instituto Federal da Bahia. E-mail: reinaldo.jose@uol.com.br , Orcid: https://orcid.org/0000-0003-3770-7862 


\title{
MENTAL HEALTH IN SEGREGATED TERRITORIES: CLINIC OF RACIST- SEXIST VIOLENCE AND PSYCHOLOGY TRAINING
}

\begin{abstract}
Segregated territories are those where public power is absent, without quality health, education and leisure equipment. The periphery is a territory in general segregated from the city center and is mainly inhabited by black and white poor populations. This work was developed in a school institution in the city of Santo Antônio de Jesus. We seek to promote mental health actions aimed at the population that inhabits the periphery. The methodology consists of health workshops, thematic conversation circles and listening to the experiences of young people and their families and teachers in the school space. The activities were organized through sociological, ethnic-racial, psychoanalytical and social psychology readings. Playful activities and workshops promoted dialogue on issues such as racism, homophobia, segregation, sexism, among others. The results show that inserting oneself in the peripheral contexts of black youth through psychology is to promote the reception of mental health and the strengthening of social criticism for the political transformation of society based on the actions promoted by the subjects involved in the context.
\end{abstract}

Keywords: racism, violence, mental health, citizenship, training in psychology.

\section{SALUD MENTAL EN TERRITORIOS SEGREGADOS: CLINICA DE VIOLÊNCIA RACISTA-SEXISTA Y FORMACIÓN EN PSICOLOGÍA}

Resumen: La segregación se produce cuando falta el poder público y faltan instalaciones sanitarias, educativas y de ocio de calidad. La periferia está generalmente segregada de la ciudad y está habitada por poblaciones pobres de blancos y negros. En este trabajo desarrollamos en una institución escolar de la ciudad de Santo Antônio de Jesus acciones de promoción de la salud mental dirigidas a la población que habita la periferia. La metodología consta de talleres de salud, círculos temáticos de conversación y escucha de las experiencias de los jóvenes y sus familias y docentes en el espacio escolar. Las actividades se organizaron mediante lecturas de psicología sociológica, étnico-racial, psicoanalítica y social. Las actividades lúdicas y los talleres promovieron el diálogo sobre temas como el racismo, la homofobia, la segregación, el sexismo, entre otros. Los resultados muestran que insertarse en los contextos periféricos de la juventud negra a través de la psicología es promover la aceptación de la salud mental y el fortalecimiento de la crítica social para la transformación política de la sociedad a partir de las acciones impulsadas por los sujetos involucrados en el contexto.

Palabras clave: racismo, violencia, salud mental, ciudadanía, formación en psicología.

\section{SANTÉ MENTALE DANS LES TERRITOIRES SÉPARÉS: CLINIQUE DE VIOLENCE RACISTE-SEXISTE ET FORMATION EN PSYCHOLOGIE}

Résumé: La ségrégation se produit là où la puissance publique est absente et où les installations sanitaires, éducatives et de loisirs de qualité font défaut. La périphérie est généralement isolée de la ville et est habitée par de pauvres populations noires et blanches. Dans ce travail, nous avons développé dans une institution scolaire de la ville de Santo Antônio de Jesus des actions de promotion de la santé mentale destinées à la 
population qui habite la périphérie. La méthodologie se compose d'ateliers de santé, de cercles de conversation thématiques et d'écoute des expériences des jeunes et de leurs familles et des enseignants dans l'espace scolaire. Les activités ont été organisées à travers des lectures sociologiques, ethno-raciales, psychanalytiques et de psychologie sociale. Des activités ludiques et des ateliers ont encouragé le dialogue sur des questions telles que le racisme, l'homophobie, la ségrégation, le sexisme, entre autres. Les résultats montrent que s'insérer dans les contextes périphériques de la jeunesse noire à travers la psychologie, c'est favoriser l'acceptation de la santé mentale et le renforcement de la critique sociale pour la transformation politique de la société basée sur les actions promues par les sujets impliqués dans le contexte.

Mots clés: racisme, violence, santé mentale, citoyenneté, formation en psychologie.

\section{INTRODUÇÃO}

A cidade de Santo Antônio de Jesus está situada no Recôncavo da Bahia. Esta região denominada Recôncavo é banhada pela Baía de Todos os Santos. Historicamente, o Recôncavo é o responsável pelo desenvolvimento da cidade de São Salvador. Há várias definições para Recôncavo por sua riqueza agrícola, cultural, econômica, através de seu patrimônio imaterial como a cultura de subsistência representada pela produção de mandioca, amendoim, cacau, laranja, coco, bananas, frutas e verduras. Bem como a produção artesanal das casas de farinha, o barro, na criação artesanal de gamelas, panelas de barro, moringas, bonecas e adornos em geral.

Também o Recôncavo possui grandes extensões de manguezais que são base de subsistência para as famílias que nele habitam. As populações que vivem à beira dos manguezais, retiram dele seu sustento, pois muitos dos produtos vindos do mangue são vendidos nas feiras livres do Recôncavo estendendo-se às feiras do Portal do Sertão. Desde os peixes até, como no passado, a cultura de plantação do tabaco.

Conforme Azevedo (2011, p.207), o Recôncavo apresenta uma importante questão conceitual. Não se pode falar de um só Recôncavo. Ele variou no tempo, em função dos seus ciclos deixando uma herança cultural, material e imaterial. Um bom exemplo da herança imaterial é a presença marcante do acarajé nas esquinas das cidades do Recôncavo.

O candomblé, religiosidade negra, também se faz presente, como patrimônio imaterial. Observa-se que no Recôncavo, as mulheres, ainda de pele retinta negra, ao 
fazerem seus bolinhos, vestem-se de branco, como as religiosas do "santo", e oferecem seu primeiro bolinho para Exu ${ }^{6}$.

Figura 1: Mapa do Recôncavo

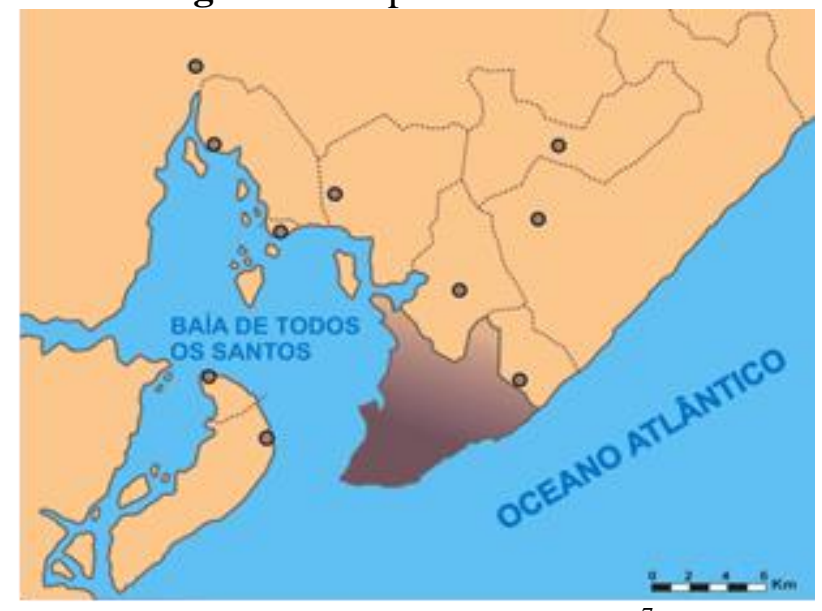

Fonte: Google imagens, $2020 .^{7}$

Figura 2: Mapa de S.Antônio de Jesus

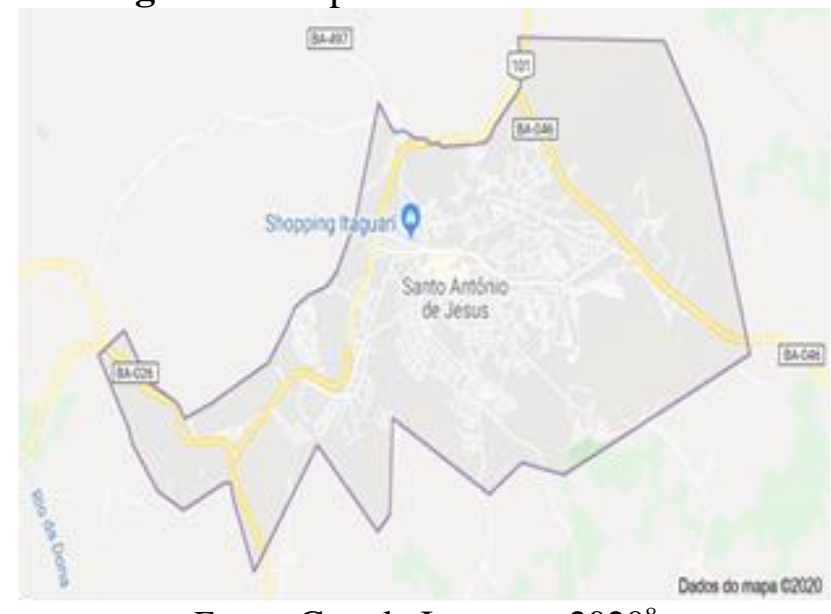

Fonte: Google Imagens, $2020^{8}$

A cidade de Santo Antônio de Jesus faz parte do Recôncavo, sua população é $74 \%$ negra e aqui, como as cidades do Recôncavo, as relações sociais são altamente racializadas, sendo naturalizada a diferença social entre brancos e negros, conforme Oliveira (2013):

\footnotetext{
${ }^{6}$ Orixá do Candomblé responsável pela transformação dos caminhos, é importante para o bom desenvolvimento do comércio.

${ }^{7}$ Disponível em: <https://www.google.com/search> Acesso em: 04 janeiro. 2020

${ }^{8}$ Disponível em: <https://www.google.com/search〉 Acesso em: 04 janeiro. 2020
} 
Em princípio, não há igualdade entre brancos e negros no Brasil; sendo assim, não havendo igualdade, a separação entre classe social e raça ganha amplas dimensões de forma naturalizada, informal e com a ação do Estado, que é a instituição expressiva das práticas de separação, controle e dominação (OLIVEIRA, 2013, p.44).

Nesta cidade observamos a vida de jovens adolescentes negros no contexto da periferia. Estes jovens e suas famílias representam e fazem parte da herança imaterial do Recôncavo, que se fundou também no colonialismo escravista. Neste território o Estado se faz ausente, apesar da presença da escola, equipamento em que realizamos nossos estudos. Ainda assim, o grupo com o qual estivemos em contato trazia durante os trabalhos os relatos da ausência do poder público dentro do ambiente de ensino. Principalmente porque careciam de equipamentos de cultura e lazer estando sujeitos às reuniões nos espaços das igrejas, principalmente as evangélicas.

Os jovens do estudo são negros e vivem nos contextos periféricos da cidade. Neste cenário podemos observar de forma geral as diversas situações de vulnerabilidade que os mesmos estão expostos cotidianamente. Estruturalmente a condição de vida na periferia é precarizada pela ausência de políticas de estado efetivas no combate à desigualdade social e racial.

Os estudos ocorreram em escola pública estadual localizada no bairro São Benedito e suas adjacências. Podemos notar as problemáticas que afetam a qualidade de vida dos indivíduos, sobretudo dos jovens negros que fazem parte do contexto escolar: observamos a ausência de saneamento básico, ausência de educação de qualidade, saúde, lazer, dentre outros elementos que causam impactos diretamente no bem-estar e desenvolvimento no período da adolescência e fase adulta, marcados de modo efetivo pela diferença de acesso às condições de uma formação geral de estudo e participação cultural formal.

Parte de nosso trabalho desenvolveu-se também no bairro Irmã Dulce, conhecido também como Mutum. E notamos a presença de um muro que separa o condomínio Arvoredo e a parte periférica deste mesmo bairro. Nesta situação observamos não apenas a segregação espacial, mas também o contraste no critério raça/cor, tendo em vista que o condomínio Arvoredo comporta a população branca e rica da cidade de Santo Antônio de Jesus, que por sua vez, utiliza a mão de obra da comunidade Mutum, pessoas e população negra e pobre. 
Estes jovens vivem em extrema violência e segregação no espaço urbano do Recôncavo em Santo Antônio de Jesus. Podemos observar que a composição desses territórios ainda possui resquícios do período que submeteu as pessoas negras a escravização. Partindo do ponto de vista que estas pessoas sempre estiveram na condição de subalternidade, sendo caracterizado pelo não acesso à educação de qualidade e, consequentemente aos melhores postos de trabalho e ascensão social, conforme Marques e Oliveira (2015):

As cidades no Brasil no decorrer do espaço tempo, sobretudo o período de 1870 a 1930, não pode ser interpretado e observado sem a história do protagonismo da população negra. Esta população, durante a sociedade escravagista, as três primeiras décadas do século XX e, principalmente no decorrer do século passado, foi responsável por todo tipo de trabalho, no campo e na cidade. Homens e mulheres negras edificaram e cimentaram as bases do desenvolvimento e da hierarquia socioeconômica do país e das principais cidades brasileiras, estas questões são observadas principalmente nos bairros periféricos das cidades (MARQUES E OLIVEIRA, 2015).

Quando observamos o espaço dividido e segregado entre os moradores do Mutum e do Condomínio Arvoredo podemos concordar que a segregação espacial é também racial. Pois nos territórios periféricos, das favelas e habitações subnormais estão majoritariamente vivendo e habitando as populações negras e não brancas (OLIVEIRA, 2013).

Enquanto no Mutum todos ou quase todos eram negros, conforme a classificação do IBGE de 2010, no condomínio Arvoredo, a notar pelos carros que lá entravam, eram em oposição quase todos, ou todos brancos. A despeito do porteiro e das trabalhadoras domésticas que morando no Mutum, realizam seu labor no condomínio de altos muros segregados.

Observar tais diferenças no espaço do território do Recôncavo é importante, pois a Bahia é o estado negro por excelência. O Recôncavo em Santo Antônio de Jesus é negro. "Então porque, se a segregação não é racial, os negros não habitam o condomínio Arvoredo? ". A afirmativa de Oliveira (2013) de que a segregação espacial é também racial é pertinente em nosso estudo. Porque observamos que os jovens que compõem a instituição escolar são majoritariamente negros, vivem com suas famílias negras ou multirraciais e, vivenciam problemáticas parecidas em suas relações sociais e demandam questões que se cruzam em determinados aspectos. 
Na sua maioria, os jovens apresentaram questões familiares, problemas dos mais sérios aos mais simples. Violências moral, agressão sexual, etc. Dificuldades em se relacionar com os pais e seus familiares, dificuldades em se expressar, silenciamento a partir de questões estruturais que contribuem para um determinado afastamento da possibilidade de comunicação.

Este silenciamento em geral apresentou-se em relação às questões religiosas de caráter evangélico protestante, o indizível contraditório opressor que se revela como a única expressão passível de ser exprimível para o jovem, negros e brancos pobres, porque permitida, autorizada e controlada. Questões ligadas à identidade de gênero e necessidade de afeto inter-relacional familiar (amor, atenção, cuidado), também se apresentaram no referente aos pais e contextos sociais e institucionais (escola e sociedade em situações de estigmas, exposição a violências e vulnerabilidades) revelando as dificuldades e sofrimentos afetivos emocionais (saúde mental abalada) por vivências em territórios esvaziados de direitos. Territórios partidos e de não cidadania.

A partir de tais considerações e alcances, objetivou-se com este favorecer as condições de reflexão dos jovens adolescentes nos territórios periféricos e segregados. Proporcionar espaços de expressão verbal e expansão de pensamento, a partir de linguagens e estéticas artísticas, psicológicas de caráter crítico e social, bem como produzir um olhar do jovem para si mesmo, na escuta de seus anseios e necessidades. $\mathrm{O}$ objetivo dos trabalhos buscou produzir um ambiente emocional e cognitivo no qual as meninas e os meninos adolescentes negros pudessem estar próximos de suas angústias e capazes de encontrarem diante de seu contexto de exclusão e vulnerabilidade, as respostas para seus conflitos e vivências, mediado pela presença dos aportes e escuta de uma psicologia materialista histórica e psicanalítica.

\section{MÉTODO}

Pensar em metodologia obriga-nos a pensar em epistemologias quando estamos desenvolvendo estudos sobre populações humanas, no caso jovens negros da periferia.

$\mathrm{Na}$ psicologia isto precisa ser emblemático, pois as dimensões emocionais e afetivas necessitam de considerações conceituais que nos auxiliem na escolha dos instrumentos que produzirão os dados importantes para aprofundamento de questões 
afetas ao fenômeno investigado a partir do contato intervencionista no campo da extensão.

Sob tal perspectiva, as leituras introdutórias em ciências sociais sobre território, sociologia urbana e relações étnico-raciais foram importantes. Na mesma medida que os estudos em psicologia e psicanálise representado por pensadoras negras como Lélia Gonzalez, Neusa Santos Souza, Virginia Bicudo e Regina Oliveira, foram leituras que compuseram a metodologia no sentido de promover as discussões e rodas de conversas com os jovens na escola.

No que diz respeito ao campo, em função da inserção do Núcleo de Estudos e Pesquisa em Psicanálise, Identidade, Negritude e Sociedade da Universidade Federal do Recôncavo da Bahia (NEPPINS/UFRB/CNPQ), possuir diferentes espaços de realização de atividades com a comunidade, recebemos convite da escola pública do bairro São Benedito para uma atividade e palestras sobre suicídio.

Realizamos o diagnóstico institucional através de reunião com a gestão escolar, buscando entender as demandas e quais as possibilidades de atenção psicossocial relativas aos serviços do Ambulatório Móvel Recôncavo Saúde: Práticas Interdisciplinares (AMORES PRA TI) os extensionistas participantes do projeto poderiam ofertar.

Posteriormente, organizamos uma proposta de ação, compreendendo a partir dos estudos epistemológicos da psicologia e ciências sociais, antropológicas e étnico raciais, como o suporte básico para a organização das atividades. Tais dinâmicas consistiram em um conjunto de estratégias que facilitassem a expressão verbal dos atores sociais implicados: os jovens adolescentes negros, meninos e meninas, bem como seus familiares no caso de estarem disponíveis.

Durante o período de quatro meses, foram organizadas as atividades e sua realização através de: a) rodas de conversa, b) bate-papo terapêutico em escutas individualizadas de questões de escolha livre pelo adolescente e quando o mesmo solicitasse, com duração média de 30 a 40 minutos no ambiente da escola em sala de orientação escolar, c) palestras sobre depressão, suicídio, automutilação, ansiedade, d) oficinas de música, dança e jardinagem, com temas variados, enfocando a saúde mental e o bem estar psíquico como atrelado aos fatos políticos, sociais, econômicos e culturais que atravessam a vida dos jovens negros na contemporaneidade e orientação semanal 
das atividades realizadas com o acompanhamento do profissional de psicologia balizando as intervenções ocorridas.

Neste sentido, a epistemologia da psicologia materialista histórica e da psicanálise por intelectuais negras brasileiras foram fundamentais para a organização da proposta de estudo e intervenção. As orientações e leituras sobre a clínica e o sofrimento psíquico por profissional da psicologia foi fundamental para o desenvolvimento dos trabalhos.

As literaturas dos autores da sociologia urbana e geografia, bem como a psicologia, saúde mental e psicanálise forneceram as bases para organizar o "bate-papo terapêutico". Esta estratégia de escuta consistiu-se de uma abertura a conversa do jovem estudante de psicologia ou enfermagem para ser capaz de ouvir o jovem estudante do ensino fundamental II. Trocando com eles algumas ideias sobre juventude, estigma, sofrimento emocional, entre outros.

Vale salientar que tanto os adolescentes participantes dos encontros, como os jovens estudantes de graduação em psicologia e enfermagem eram jovens negros em estágios próximos de desenvolvimento geral. Jovens da graduação entre seus 19 e 22 anos e jovens do ensino fundamental II entre 12, 13 e 14 anos. Esta coincidência parece ter proporcionado um bem-estar adicional para os dois grupos de jovens negros: estudantes de escola pública da periferia e estudantes negros da Universidade Pública Federal. Potencializando os dois lados da produção em saúde mental coletiva, pois:

A Agenda de Prioridades de Pesquisa em Saúde - campo dialógico da psicologia - referenda que há extrema defasagem no campo conceitual da formação profissional e intervenção em saúde no que diz respeito à saúde da população negra, violência e agravos à saúde - principalmente contra jovens negros e saúde mental. Sendo este - a saúde mental - campo inerente à psicologia (OLIVEIRA, 2017, p.154).

A produção coletiva de saberes formais entre jovens negros em iniciação de pesquisa e atividades de intervenção à comunidade, bem como a participação protagonista da juventude negra, é fator emblemático e importante para validar ações importantes e pouco frequentes no cenário formativo da academia brasileira. O ganho é extremamente expressivo para a comunidade científica, acadêmica e social.

\section{SABERES PRODUTIVOS E SABERES COMPARTILHADOS}


O "bate-papo terapêutico" possui um caráter de participação e produção coletiva a partir de ideias expressadas através de uma música, um desenho, um livro, um objeto de escolha do adolescente, que possa provocar uma ideia, uma imagem, um disparador para a fala.

Num primeiro momento os objetos e recursos foram utilizados. Porém, no decorrer dos encontros da sala de bate-papo tudo se tornou mais fluido e espontâneo. Os jovens não precisavam mais dos recursos e objetos do baú terapêutico. Eles simplesmente sabiam do tema que queriam conversar e se expressavam oralmente.

Utilizamos uma caixa que denominamos Baú Terapêutico, no qual havia alguns instrumentos que pudessem favorecer o diálogo dos jovens com o estudante de psicologia ou enfermagem, trocando ideias sobre o que é ser jovem no contexto da diáspora negra, no contexto da periferia pobre, no contexto do estigma social, no contexto das dificuldades familiares e econômicas. Os assuntos também procuravam dialogar com o calendário pedagógico da escola, como por exemplo o "Setembro Amarelo" e outros temas pertinentes ao sofrimento mental no espaço escolar.

Após as atividades iniciais, algumas demandas dos estudantes participantes foram percebidas e por meio disso foi reelaborado um cronograma das atividades que seriam realizadas. Inicialmente, ficou definido que durante uma vez na semana seriam realizadas oficinas grupais com exercícios variados que pudessem fomentar o debate e a elaboração coletiva de questões em torno da saúde mental. Utilizamos instrumentos que tem conexão com a realidade dos jovens e adolescentes em idade escolar, foram utilizadas nas oficinas a técnica de análises de músicas, dinâmicas grupais e diálogos sobre saúde mental.

$\mathrm{Na}$ atividade "bate-papo terapêutico", os estudantes de graduação puderam desenvolver uma escuta sensível, capaz de perceber vivências de sofrimento psíquico. Os jovens externalizavam seus anseios, angústias e problemáticas levantadas nas atividades em grupo e a partir disso os estudantes de psicologia ou enfermagem, buscavam entender os fatores de sofrimento contidos nos relatos apresentados e construíam de maneira conjunta reflexões sobre as vivências dos jovens e adolescentes no contexto escolar e familiar. Foi observado que conteúdos voltados para violências racializadas e de gênero estavam sempre muito presentes nos temas problemas dos jovens. A estas ideias percebemos o caráter da violência racista e sexista predominante 
no ambiente periférico dos meninos e meninas negras no território segregado do Recôncavo da Bahia.

Aliado a isso, durante todas as etapas de compreensão das demandas do grupo, de levantamento das práticas necessárias e das questões levantadas individualmente no bate-papo, a orientação teve papel fundamental em indicar as leituras e estudos sobre os conceitos e teorias que conseguiriam dialogar com a realidade dos participantes.

\section{RESULTADOS E DISCUSSÃO \\ ELABORAÇÃO E EXECUÇÃO DAS PROPOSTAS DE INTERAÇÃO}

Conseguiu-se finalizar o trabalho que efetivou-se objetivamente no seguinte formato: Duas atividades semanais, sendo elas as oficinas terapêuticas e o bate-papo terapêutico, utilizamos como instrumento o baú terapêutico, conforme acima explicamos na metodologia. Nas oficinas terapêuticas foram desenvolvidas as seguintes atividades: a) Oficina de Jardinagem e Prevenção ao suicídio; b) Oficina de Análise de Músicas I; c) Oficina de Análise de Músicas II; d) Oficina de Dança Terapia e Consciência Corporal; e) Oficina de Imagens sobre Amizades e Relações Familiares.

$\mathrm{Na}$ execução das atividades observou-se que foi possível atingir os objetivos propostos, pois os jovens conseguiram falar de seus sofrimentos e de suas angústias. Percebeu-se no contexto da escola que o ambiente tornou-se mais produtivo e menos tenso. Os jovens durante o processo de realização das oficinas no período de cinco meses puderam ouvir melhor os colegas, posicionarem mais a própria fala, demonstraram maior conexão consigo mesmos e com as relações que foram pouco a pouco construídas no percurso do grupo.

No mesmo sentido os jovens negros estudantes de psicologia podiam refletir sobre as dificuldades de acolher a angústia dos jovens. Nada era possível fazer para minorar a dor e, o sofrimento que longe de ser essencialista, da ordem de um psicologismo e psicanálise histórica, são inerentemente densos de questões sociais, econômicas e culturais que desqualificam e despotencializam os sujeitos historicamente subalternizados.

Na discussão com os estudantes de graduação a percepção da violência racista no próprio ambiente escolar era visível, considerando que a gestão escolar em sua 
maioria branca, desqualificava o trabalho dos estudantes negros da universidade, com palavras "pena que ninguém valoriza o trabalho de vocês", "puxa, estes jovens não querem nada, com nada".

No entanto, percebeu-se que quando a gestão foi ocupada por uma professora negra, os estudantes de graduação em psicologia e enfermagem passaram a receber merenda que era servida por uma funcionária da escola. Passaram a ter uma jarra de inox com água gelada durante as oficinas. Os alunos, estudantes negros da escola, passaram a receber alguns brindes depois da oficina, como bombons, pirulitos, plantinhas, entre outros. A violência racista/sexista se manifesta nas entrelinhas das ações institucionais. O enredo do racismo na escola é estrutural e institucionalizado.

No contexto da análise interpretativa da psicologia podemos afirmar que uma gestão branca tem dificuldade de perceber as narrativas da população negra, desqualificando seu lugar de empoderamento e subestimado a capacidade de reação dos historicamente martirizados. De tal maneira, entende-se que a fala "que pena, ninguém valoriza vocês..." está muito mais relacionada com o desejo inconsciente, ou talvez nem tão inconsciente de apagar o protagonismo negro, de invisibilizar as produções negras que agregam valor formativo ao processo civilizacional das populações humanas.

Sob esta perspectiva, os resultados foram muito positivos, pois elevaram a crítica social dos estudantes extensionistas, bem como favoreceu o empoderamento negro na linguagem afirmativa de seu posicionamento diante de espaços de clausura e entorpecimento político cognitivo.

A fala da gestora, que era uma mulher branca, e não implicada com o sofrimento dos sujeitos negros na escola, e tão pouco grata com a presença da universidade (alunos negros de graduação em psicologia e enfermagem), no apoio ao desenvolvimento dos escolares, revela o pacto narcísico da gestão com o projeto colonialista das escolas brasileiras no que tange a formação histórica desse contexto de dominação, coerção e poder.

Em nossa análise, o que se quer e preconiza na escola do território segregado com gestores que reproduzem ideias colonialistas é:

(...) o sujeito obediente, o indivíduo sujeito a hábitos, regras, ordens, uma autoridade que se exerce continuamente sobre ele e em torno dele, e que ele deve deixar funcionar automaticamente nele (...). Formar um sujeito de 
obediência dobrado à forma ao mesmo tempo geral e meticulosa de um poder qualquer (FOUCAULT, 2005, p.106)

As meninas e meninos negros do contexto da escola da periferia do recôncavo, com a presença de estudantes negros de graduação em psicologia e enfermagem, puderam empoderar-se de si mesmos. Perceber sua história e seu valor. Sua ancestralidade negra e sua potencialidade de origem, presente e futuro.

A obediência cega a um qualquer, que reduz o protagonismo do sujeito, encerrando-o em quadro doentio de adoecimento e sofrimento mental e físico orgânico (ansiedade, medo, sudoreses, pânico, tentativas de suicídio e automutilação, cada vez mais comum no contexto escolar pobre, negro e periférico), passou a ganhar a liberdade do pensamento. Liberando-se do pensamento único para alçá-lo na esperança e no otimismo da viabilidade de seus desejos e de sua vida, potencializando espaços de trabalho e crescimento coletivo.

A produção do enredo entre jovem negro estudante da universidade se elevou na troca da dádiva que o sofrimento do estudante negro da escola periférica pode enfrentar, compartilhar e buscar saídas criativas para seu potencial humano e civilizacional.

O projeto de encarceramento branco, racista e sexista - porque o protótipo colonizador é branco, masculino e poderoso economicamente - foi deflagrado de seu poder preconizado de exigências de subalternidades e violências.

Estudantes negros falaram e protagonizaram pelo conhecimento e produção de saber a voz de suas vidas: jovens graduandos de psicologia e enfermagem e estudantes adolescentes do ensino fundamental II.

\section{GRUPO DE ESCUTA TERAPÊUTICA “SAÚDE MENTAL, VIOLÊNCIA E}

\section{RACISMO"}

Nos primeiros encontros percebemos o quão necessário seria o desenvolvimento de atividades que permitissem a fala, bem como a necessidade de escuta. Por estar trabalhando com um grupo específico vindo do contexto periférico, no qual as várias formas de violências são incessantes, buscamos não impor nossos conhecimentos, mas mostrar para aqueles jovens que as oficinas terapêuticas tinham justamente o objetivo de contribuir para eles refletirem sobre suas realidades e, a partir disso, externalizar. Questão que é importante na psicologia, pois o próprio sujeito pode buscar 
transformações para a sua condição atual quando a ele é permitida uma reflexão crítica acerca do que é ser negro na sociedade brasileira, segundo Souza (1983):

Ser negro é tomar consciência do processo ideológico que, através de um discurso mítico acerca de si, engendra uma estrutura de desconhecimento que o aprisiona numa imagem alienada, na qual se reconhece. Ser Negro é tomar posse desta consciência e criar uma nova consciência que reassegure o respeito às diferenças e que reafirme uma dignidade alheia a qualquer tipo de exploração. Assim, ser negro não é uma condição dada, a priori. É um vir a ser. Ser negro é tornar-se negro (SOUZA, 1983).

Por meio do grupo de oficinas terapêuticas foi possível notar uma evolução dos participantes em relação às diversas temáticas abordadas. Os principais temas abordados foram as questões de Saúde Mental, Depressão, Gênero, Relações Familiares, Identidade, Racismo. Tornou-se cada vez mais notável a disponibilidade dos estudantes em participar das atividades, debater e problematizar as temáticas, assim como o respeito à fala dos demais colegas. Esses comportamentos coletivos revelam uma internalização dos conhecimentos construídos coletivamente, assim como o cuidado em abordar e entender suas próprias questões afetivas, e a capacidade de enxergar mais amplamente os processos psíquicos que vem ocorrendo em suas vidas.

A saúde mental foi abordada a partir do acolhimento pela escuta e pela palavra. A linguagem revela-se como campo curativo, entre o interesse de ser ouvido e a capacidade de disponibilizar-se como uma espécie de medicamento que produz bemestar e cura, nesse sentido:

O ser humano não é um ser que parou sua constituição no plano biológico, e a fisiologia do ser humano é diferente, à medida que o homem passa a viver sobre a influência da cultura (...) A biologia do ser de linguagem é subvertida, ela se deforma para estruturar-se numa outra lógica, que não é a lógica do instinto, a lógica da biologia, mas na lógica da pulsão (RANNÃ, 2001, p.76).

A lógica da pulsão é a lógica da vida, do sonho, do prazer, da fantasia, lembrando que a fantasia, conforme Klein (2001), é o prenúncio do pensamento.

Pensar juntos, refletir juntos e promover o diálogo na expansão do campo da cultura formal e do campo da consciência do sujeito, foi promotor de saúde mental para os jovens negros dos territórios segregados. 
Promover o debate sobre cidadania, direito à habitação, estigmas, vulnerabilidades e preconceitos, retirou desses jovens, como que por catarse, parte do sofrimento psíquico vivido pela atrocidade do racismo.

Quando informamos racismo estamos considerando que a estrutura racializada da escola, sua gestão, sua forma de acolher e considerar o sujeito dentro das amarras das regras rígidas e dos cerceamentos do pensamento dos jovens e não acolhimento da família, gera o entorpecimento do corpo. O encolhimento do sujeito, o reducionismo da vida.

Obviamente a escola não é a única responsável por estas circunstâncias, mas ela é coparticipante no processo de promoção de saúde e adoecimento dos sujeitos.

A escola nos territórios segregados pode favorecer a revisão crítica da sociedade, pode tentar promover a ordem da cultura, da leitura do mundo social, promovendo o acesso ao ambiente do conhecimento geral e de modo compartilhado, interessando-se pela vivência dos alunos e seus interesses, favorecendo o diálogo com as famílias que necessitam de esperança diante dos apelos do consumo, das drogas, do sexo fácil, da vida inútil na sociedade líquida onde os laços humanos são fragilizados e não há compromisso com o outro, muito menos com o seu sofrimento emocional.

A formação do estudante do campo da saúde mental, foi favorecida pela vivência neste território da pobreza, da marginalidade periférica, dos caminhos sem asfalto e mal iluminados.

Os estudantes negros de psicologia e enfermagem puderam valorizar as mensagens e saberes tímidos que se apresentavam nas vozes das jovens meninas negras, temerosas pelos olhares curiosos e desejosos sobre seus corpos quase sempre violados em sua beleza, quase sempre desprezados em suas necessidades de palavras e linguagens.

Uma das componentes do grupo havia presenciado a morte de um jovem nas imediações a escola. Ao mesmo tempo que os noticiários nacionais divulgavam a tragédia da cidade de Suzano, onde um jovem atirou de modo frio e sem razão em vários estudantes no interior de uma escola.

Este fato foi traumático para muitos jovens, que diante da vulnerabilidade da vida sentem-se sempre ameaçados.

É como sentir a violência do massacre homicida dos genocídios reiteradamente praticados contra os jovens negros nas esquinas das favelas e periferias dos territórios 
sem lei, nos espaços sem cidadãos: todos estamos sujeitos ao massacre, mesmo que nenhum crime tenhamos feito. Era o indizível que se apresentava nas falas da família da jovem adolescente negra que vivia em constante estado depressivo, assim como muitos outros jovens apresentavam episódios de estados depressivos graves e crises de tentativas de automutilação.

Esta abordagem de construção de conhecimento do psiquismo aliado a dimensões sociais e políticas puderam ganhar materialidade no inter-jogo das relações e produções apresentadas para os jovens.

O processo de construção em saúde mental para a população negra deve passar por dispositivos como estes proporcionados pela atividade realizada, que permitam a emancipação da fala do sujeito, que o libere de ideias vitimistas (como "elevar a autoestima do sujeito negro”) para posicioná-lo no lugar de percepção de si mesmo e do contexto de violência social e psíquica: quais as atrocidades que me foram cometidas e quais os enredos passíveis de reconstrução de minhas feridas?

O processo emancipatório favorece o discernimento da consciência, pois todo ato psicanalítico, toda escuta psicanaliticamente orientada, como a que se produziu na base dos textos lidos nas vozes de psicanalistas mulheres e negras, é um embate de produção da consciência. A psicanálise foi a descoberta do inconsciente. Mas seu método visa em primeira e última instância a retirada do sujeito de seu letárgico estado de inconsciência.

$\mathrm{O}$ advento psicanalítico é o desvendamento do inconsciente e, portanto, o investimento no método para o fortalecimento do ego, o equilíbrio pela consciência.

A resolução pelo enigma da esfinge; conhece e revela-te a si mesmo.

Lembrando a todos que a Esfinge fica no Egito. De onde provém grande parte dos mitos gregos 9 .

Se Freud descobriu ou inventou a psicanálise e foi o pensador do século vinte a partir da genialidade da importância dos processos oníricos, os africanos, desde sempre até os dias atuais, sempre souberam e praticaram a importância dos sonhos na vida e civilização negro africana há muito tempo e bem antes de Freud.

Não é porque você não sabe que algo simplesmente deixa de existir.

\footnotetext{
${ }^{9}$ Cheikh Anta Diop no livro Nations nègres et culture nos informa sobre a influência egípcia na cultura e civilização grega. Informa também as várias influências da cultura egípcia nas civilizações europeias como a romana e o culto a deusa egípcia e negra Isis, na Alemanha. DIOP, p.176
} 
Infelizmente este é o pensamento ocidental sobre seu processo de produção de conhecimento, inclusive na saúde mental e psicologia. A necessidade de produzir o apagamento dos sujeitos negros, revela a incapacidade de admitir linguagens da diversidade. A prova disto é o desconhecimento nos currículos nas faculdades e universidades de psicologia do Brasil de pensadoras negras ícones da psicanálise como Neusa Santos Souza e Virgínia Leone Bicudo não serem sequer citadas na bibliografia de um projeto pedagógico curricular no Brasil negro?

Os desafios de produzir uma psicologia promotora de saúde mental no Recôncavo e no Brasil, passa necessariamente pelo descortinamento do racismo institucionalizado nos bolsões de pobreza e marginalidade nos territórios segregados.

Passa necessariamente pela discussão com estudantes em início de exercício de pesquisa e extensão das inconsistências do fazer psicológico no Brasil. Das artimanhas do poder branco que se engendra na constituição do profissionalismo da "ciência psicológica".

Esquecendo-se que a psicologia brasileira iniciou-se, conforme Antunes (2015), a partir da preocupação dos jesuítas em desenvolverem técnicas de persuasão de selvagens. Os selvagens para eles eram os indígenas. Para nós, podemos dizer que foram cientistas tecnológicos de alto gabarito, sabedores milenares, que transformaram a raiz da mandioca, aipim, antes venenosa, em produto comestível de alto valor nutritivo e de culinária vasta (DARCY RIBEIRO, 2005)

Tais reflexões e discussões nas oficinas produzidas, favoreceram o desenvolvimento dos trabalhos na perspectiva dos sujeitos da academia, bem como dos sujeitos protagonistas no contexto da escola da negritude da periferia.

Inverter a lógica da produção dos saberes foi um importante jogo não premeditado no decurso das atividades promovidas e articuladas no grupo e nas oficinas e escutas-linguagens com os adolescentes negros.

A lógica invertida - negros estudantes de psicologia e enfermagem e negros adolescentes da periferia - produziu o fortalecimento de ambos os sujeitos.

Psiquicamente, ser negro, comporta nesta sociedade ocidentalizada e tecnicamente preparada e engajada para o apagamento e invisibilidade das populações não brancas (negros e indígenas) comporta sofrimento incomensurável.

Para o estudante negro de psicologia do Recôncavo e também em alguma medida para o estudante de enfermagem, a validade de seu saber está sempre fora dos 
livros e validades epistemológicas clássicas trazidas pelos "saberes" dos professores. Representantes da ciência válida.

Assim sendo, ser negro é promover ações em saúde mental para populações excluídas do debate nacional e internacional, é refletir sobre si mesmo. É tornar-se negro na capacidade de produzir um diálogo epistemológico que rompa com as amarras do racismo infiltrado nas tramas da academia brasileira.

A invisibilidade dos corpos negros, são o massacre genuíno que a academia promove. Porque negar as literaturas negras e as presenças negras nos espaços formadores universitários em saúde e saúde mental para manter os padrões eurocêntricos formativos, representa o colonialismo vigente nos dias de hoje na universidade brasileira. Principalmente no campo psicológico e em saúde mental.

\section{LIMITES E ENTRAVES: A CLÍNICA DA VIOLÊNCIA E A VIOLÊNCIA DO CONTEXTO RACIALIZADO}

Toda a experiência realizada pautou-se no campo da clínica psicológica em seu sentido estrito: pensar a dinâmica emocional dos sujeitos em relação ao espaço da vida em sociedade. Por isso toda a atividade realizada pôde ser considerada como uma clínica eu observa a violência racista no contexto da escola no Recôncavo da Bahia.

A clínica, enquanto trabalho de campo exige dedicação e há interferências de acordo com as relações que são estabelecidas. Na instituição escolar que desenvolvemos as atividades observamos que inicialmente havia uma gestão extremamente preocupada com o desenvolvimento do projeto de extensão. Todas as vezes que os extensionistas chegavam na escola as salas da execução das atividades já estavam organizadas. Podemos perceber que era disponibilizado lanche, água e os instrumentos necessários para o pleno funcionamento das atividades.

Por um lado, percebe-se que uma das gestoras tinha o compromisso ético tanto com a escola quanto com os extensionistas, uma vez que o estado disponibiliza recursos para efetivar, ainda que de maneira precarizada, o funcionamento da instituição pública. Por outro lado, em um contexto racializado, não há como não observar as contradições após a reinserção da antiga gestão, que por sua vez, reproduzia a violência racializada. Notamos que após essa nova gestão assumir a liderança as atividades do projeto começaram a ser prejudicadas, pois chegávamos na escola e o espaço físico e 
instrumentos não encontravam-se organizados para a condução da atividade, e esta diferença de gestão aparecia de maneira gritante na tonalidade da pele - de um lado uma gestão negra retinta, de outro uma gestão branca.

Dessa forma, fica evidente que tudo muda conforme a visão da gestão relacionada a importância de atividades relacionadas a saúde mental no contexto escolar. A violência racista se manifesta principalmente quando os extensionistas são todos negros, e por esse motivo a gestão tenta deixar nítido que o desenvolvimento das atividades não tem importância no contexto, buscando meios que ceifam o desenvolvimento das atividades de maneira plena. A principal contradição é gritante quando percebe-se o interesse da gestão negra tanto em inserir as atividades na escola quanto a manutenção da mesma e por outro lado a tentativa de interrupção dela pela gestão branca.

As políticas de estado são fundamentais para sanar as necessidades demandadas para a efetivação do trabalho. Durante o período do desenvolvimento das atividades no colégio conseguimos observar que a maioria das violências vivenciadas pelos jovens poderiam ser amenizadas a partir da atuação de uma gestão escolar mais compromissada com a qualidade de vida dos estudantes, tendo em vista que as questões observadas desencadeiam dificuldades inclusive no desenvolvimento do estudante.

Por exemplo, nas situações de agressão física a presença de um assistente social no âmbito escolar seria crucial para observar o porquê tais jovens estavam indo para a escola com sequelas de agressões e, a partir disso, notificar os pais de maneira que os responsabilizassem a cuidar do filho de maneira mais responsável, ao invés de agredilos.

Além disso, no caso dos jovens que apresentam maior vulnerabilidade socioeconômica, o estado tem a função de promover políticas equânimes que dialoguem com a realidade desta juventude, resgatando a importância de mantê-los no contexto escolar e afastá-los da possibilidade de inserção na criminalidade, pois a violência racista é poderosa munição para a maior parte dos problemas sociais e econômicos.

\section{CONCLUSÃO}

Os desafios das formações em psicologia e enfermagem enquanto sujeito negro numa sociedade racializada torna-se bastante complexa, principalmente porque os 
indivíduos negros foram historicamente afastados da intelectualidade por meio da sua inserção no mercado de trabalho farto e barato. Somado a isso, no início da sua história a psicologia foi pensada por homens brancos europeus que tinham como principal objetivo utilizá-la como uma maneira de condicionar pessoas, sobretudo negras, a altas jornadas de trabalho. A produção capitalista buscava, e ainda busca de modo sempre violento e perverso principalmente contra jovens, mulheres, negros, crianças, entre outros, independente das consequências, a produção lucrativa.

Atualmente, através da luta dos movimentos sociais, sobretudo o movimento negro, estas práticas sofrem a resistência e passam a impor novas transformações e paradigmas nas relações frente aos direitos sociais e cidadania. A psicologia diante deste novo cenário precisa passar a atuar de maneira equânime, mais próxima e vinculada à população negra e pobre pertencente majoritariamente à realidade brasileira, e com maior compromisso qualitativo.

Como estudantes negros de psicologia observamos que muitas dificuldades se impuseram na nossa atuação e por consequência na nossa formação por conta do racismo institucional vivenciado, tanto na instituição de ensino quanto nos locais que são desenvolvidos os estágios e atividades de extensão. Percebemos as tentativas de silenciamento diante de nossos fazeres e propostas de modo reiterado e constante. As gestões dos equipamentos sociais e instituições afirmam seu lugar de fala e de poder reproduzindo um modelo colonialista escravista, no qual os sujeitos vistos como diferentes são preteridos no contexto da atuação da saúde.

Por outro lado, a estética negra do grupo que produziu aas atividades de extensão de certo modo afirmou o modelo positivo da estética negra, possibilitando identificações com os estudantes negros do ensino fundamental II e familiares.

Neste sentido, a psicologia se efetiva enquanto um dos principais instrumentos no combate às diversas formas de violências enfrentadas pelos indivíduos residentes em contextos periféricos. No colégio percebemos o quão transformadora foi a nossa presença, pois se o estado é falho na inserção das políticas, as atividades de extensão quando são oportunizadas devem ser desenvolvidas da maneira compromissada epistemologicamente com uma ética que subverta os valores eurocêntricos para anunciar práticas libertárias, não excludentes e não segregacionistas. Favorecendo os que vivenciam a segregação sócio espacial e racial, ainda mais quando s protagonistas destas ações são oriundos de um contexto semelhante. Os jovens estudantes de 
psicologia, enfermagem e medicina, pertencem ao cenário da negritude jovem, negra e periférica do contexto do interior da Bahia. Protagonistas do presente, eles, jovens estudantes da escola pública periférica e jovens estudantes da universidade pública brasileira espelham-se no reflexo de nossos tempos. Enclausuramentos que anunciam a liberdade - típica força da diáspora negra presente.

Concluímos este trabalho ratificando a sua importância para a formação em psicologia, enfermagem e medicina. Agradecendo ao contexto Reconvexo - região na qual a presença das religiões africanas se impõe no chão das cidades na expressão dos terreiros. O chão do território, o terreiro da cidade, marcham os sonhos das juventudes negras, e são ricos, por sua diversidade e resistência. Direcionamos também nossos agradecimentos ao território e instituição escolar que nos recebeu, bem como ao Núcleo de Estudos e Pesquisas em Psicanálise, Identidade, Negritude e Sociedade - NEPPINS que acolhe as atividades do projeto e ao Programa Institucional de Bolsas de Extensão Universitária - PIBEX, da Universidade Federal do Recôncavo da Bahia.

\section{REFERÊNCIAS BIBLIOGRÁFICAS}

ANTUNES, Mitsuko. História da psicologia no Brasil. EDUC: São Paulo, 2015.

AZEVEDO, Paulo Ormindo de (Org.). Bahia de todos os santos: Recôncavo: território, urbanização e arquitetura. EDUFBA: Salvador, 2011.

OLIVEIRA, Reinaldo José, OLIVEIRA, Regina Marques de Souza « Origens da segregação racial no Brasil », Amérique Latine Histoire et Mémoire. Les Cahiers ALHIM [En línea], 29 | 2015, Publicado el 18 junho 2015, consultado el 14 enero 2020. URL: http://journals.openedition.org/alhim/5191

OLIVEIRA, Regina Marques de Souza. Cenários da Saúde da população negra no Brasil diálogos e pesquisa. EDUFRB: Cruz das Almas, 2016.

OLIVEIRA, Reinaldo José de. A cidade e o negro no Brasil: cidadania e território. Alameda Editora: São Paulo, 2013.

OLIVEIRA, Regina Marques de Souza. A formação do psicólogo nos contextos da diáspora africana. In: Oliveira, R.M.S (org.). Dilemas da raça: empoderamento e resistência, Alameda Editora: São Paulo, 2017.

DIOP, Chieh Anta. Cátions migres et cultura. Paris: Présence africaine, 1979.

FOUCAULT, Michel. Vigiar e Punir - história da violência nas prisões. Petrópolis: Editora Vozes, 2005. 
RANÃ, Wagner. A doença no corpo: efeitos do contemporâneo ou resultado de uma nova leitura. In: A criança na contemporaneidade e a psicanálise. Comparato, M.C.M. (org.). São Paulo: Editora Casa do Psicólogo, 2001.

REIS, Alcides Manoel dos. Candomblé: a panela do segredo. (Org.) Rodnei William Eugênio. São Paulo: Mandarim, 2000.

RIBEIRO, Darcy. O povo brasileiro. São Paulo: Companhia das Letras, 2000.

SOUZA, Neusa Santos. Tornar-se Negro. Rio de Janeiro: Editora Graal, 1983.

KLEIN, Melanie. Inveja e gratidão. Imago: Rio de Janeiro, 2001.

Recebido em: 22/09/2020

Aceito em: 30/10/2020 